\title{
Gravity-induced stress as a factor reducing decay of sandstone monuments in Petra, Jordan
}

Jaroslav Rihosek ${ }^{a}$, Jiri Bruthans ${ }^{a,{ }^{*}}$, David Masin ${ }^{a}$, Michal Filippi ${ }^{b}$, Gregory T. Carling ${ }^{c}$ and Jana Schweigstillova ${ }^{d}$

aFaculty of Science, Charles University in Prague, Albertov 6, 12843 Prague 2, Czech Republic bInstitute of Geology, CAS, v. v. i., Rozvojova 269, 16500 Prague 6, Czech Republic 'Brigham Young University, Department of Geological Sciences, Brigham Young University, Provo UT 84602, USA

dInstitute of Rock Structure and Mechanics, CAS, v. v. i., V Holesovickach 41, 18209 Prague 8, Czech Republic

*Corresponding author: Tel.: +420 221951566

E-mail address: bruthans@natur.cuni.cz

\section{Abstract}

Recent work has shown that gravity-induced stress within a landform due to vertical loading reduces weathering and erosion rates, contrary to commonly held hypotheses. The purpose of this investigation is to evaluate the negative feedback between stress and weathering of sandstone monuments at the Petra World Heritage Site in Jordan via field observations, salt weathering experiments, and physical and numerical modeling. Previous studies on weathering of Petra monuments have neglected the impact of stress, but the ubiquitous presence of stress-controlled landforms in Petra suggest that it has a substantial effect on weathering and erosion processes on manmade monuments and natural surfaces. Laboratory salt weathering experiments with cubes of Umm Ishrin sandstone from Petra demonstrated the inverse relationship between stress magnitude and decay rate. Physical modeling with Střeleč locked sand from the Czech Republic was used to simulate weathering 
and decay of Petra monuments. Sharp forms subjected to water erosion decayed to rounded shapes strikingly similar to weathered tombs in Petra. The physical modeling results enabled visualization of the recession of monument surfaces in high spatial and temporal resolution and indicate that the recession rate of Petra monuments is far from constant both in space and time. Numerical modeling of stress fields confirms the physical modeling results. This novel approach to investigate weathering clearly demonstrates that increased stress decreases the decay rate of Petra monuments. To properly delineate the endangered zones of monuments, the potential damage caused by weathering agents should be combined with stress modeling and verified by documentation of real damage.

Keywords: sandstone monument, stress, stability, decay, Petra

\section{Introduction}

Weathering of manmade sandstone monuments is an important problem studied by a variety of approaches [1-4]. Gravity-induced stress (hereafter "stress") is a phenomenon that is widely considered to limit the stability of sandstone monuments if rock strength is exceeded, and its effect on weathering or erosion rate is generally neglected [5-7]. However, Bruthans et al. [8] demonstrated that stress plays a crucial role in the origin of common natural sandstone landforms like pillars, arches, alcoves, and pedestal rocks, and showed that these landforms are actually stress-controlled wherein stress causes the rock to resist weathering. Various weathering and erosion processes (e.g., salt and frost weathering, raindrop impact, overland flow, slaking) proceed faster on surfaces with lower stress and are considerably less erosive in areas with higher stress. Erosion and weathering are coordinated by the stress field to reshape the original rock exposure into a new geometry where low-stress portions (i.e., portions with low loading) are removed. This idea is supported by evidence from both physical modeling with real sandstone under controlled conditions and numerical modeling. 
The effect of stress on weathering and decay might be readily observable at manmade sandstone monuments exposed for sufficient time. The Petra World Heritage Site in Jordan, with well dated monuments, is an excellent laboratory to investigate clearly defined long-term weathering rates. Several hundred tombs were carved in Paleozoic sandstones by the Nabatean civilization in Petra between 200 B.C and 150 A.D. [9]. Similar Nabatean tombs can also be found at generally lesser known Al-Hijr (Madâin Sâlih) site in northern Saudi Arabia. Reported recession rate of tomb facades and other outer sandstone surfaces range from 0 to $350 \mathrm{~mm} / \mathrm{kyr}$ [10-13]. Salt weathering, flowing water during rain storms, hygric swelling, and insolation are considered the major weathering processes responsible for sandstone decay $[9,11,13]$. In many cases, monuments carved by the Nabateans have degraded into pillars and arches and rectangular openings have become rounded, suggesting that weathering is controlled by stress fields. However, the effect of stress on weathering has not been considered in previous studies on Petra [9-14].

The purpose of this study is to assess the effect of stress on weathering and decay of monuments carved into sandstone in Petra. This is accomplished by four complementary approaches:

i) Document landforms that appear to originate from the negative feedback between stress and weathering on manmade monuments and natural rock exposures;

ii) Evaluate the relationship between stress and decay rate via salt weathering experiments;

iii) Perform physical modeling experiments on simplified downscaled replicas of Petra monuments to simulate weathering processes; and

iv) Develop numerical models to evaluate stress-controlled erosion of replica monuments over time.

\section{Geological settings and material characteristics}

\subsection{Petra sandstone monuments}


Petra is situated in southern Jordan on the eastern rim of Dead Sea rift valley at an elevation of $900-1100 \mathrm{~m}$ a.s.I. [15]. Mean annual precipitation is $298 \mathrm{~mm}$ and rain occurs mainly during winter [16]. Mean annual temperature is $22^{\circ} \mathrm{C}$ [17]. Cambro-Ordovician sandstones, which host Nabatean monuments, were deposited on the Precambrian igneous basement complex and are covered by Lower Cretaceous sandstones [15]. Two formations within the CambroOrdovician sequence are exposed: the Umm Ishrin formation overlain by the Disi formation $[9,13]$. Umm Ishrin and Disi sandstones (total thickness of $\sim 500 \mathrm{~m}$ ) were deposited in an alluvial braided plain and dip gently to the east $\left(09^{\circ}\right)$ [15]. The $\sim 400 \mathrm{~m}$ thick Umm Ishrin sandstone consists of multicolored medium-coarse grained and well sorted quartz combined with highly variable proportions of authigenic kaolinite, hematite, goethite, and subordinate calcite as a cementing material [18]. Total porosity varies between 4 and $21 \%$ and matrix content varies between 7 and 50\% [13]. The $~ 100 \mathrm{~m}$ thick Disi formation consists of mostly whitish-beige color coarse-grained sandstone with prevailing quartz and subordinate feldspar. Secondary quartz and clay minerals are the main cementation components with minor hematite and calcite. Diagenetic cementation is characterized by syntaxial quartz overgrowth [9].

\subsection{Weathering of Petra sandstone}

The ancient city of Petra is a unique architectural/historical monument with columns, cornices, metopes, triglyphs and friezes carved into sandstone [19]. Many shapes like tomb chambers were originally rectangular with mostly rectangular openings (Fig. 1). The weathering of artificial forms in Petra has resulted in rounded shapes remarkably similar to those commonly found in surrounding natural sandstone cliffs and also in cliffs of the same lithology over a wider area [e.g., 20]. Tafoni, channels, cavities, rillen, stonelace, pits and spalled surfaces are found on both natural and manmade monuments $[11,14]$. Wedekind and Ruedrich [9] recognized two kinds of tafoni: i) horizontal alveolar running below and markedly above ferruginous zones with water-damping effects that bring salt-rich moisture to the sandstone surface; and ii) vertical with narrow strips of temporary flowing water from storms. 
Salt weathering is one of the most important factors controlling deterioration of Petra monuments based on field evidence and the high sensitivity of Umm Ishrin sandstone to salt weathering tests [9]. Salts in Petra primarily consist of halite and gypsum with minor amounts of other salts $[9,13]$. A considerable proportion of salt components (up to $10 \mathrm{wt} . \%$ ) is derived from rain and occurs in the first few centimeters of the depth profile of tafoni [9,13]. Rain, water flow on sandstone exposures, flash floods, and humidity are also contributing factors for weathering [13]. Paradise [10] suggested that insolation is an important factor in decay but Heinrichs [13] found no correlation between insolation and weathering damage. Wind contributes to erosion of loosened stone material and evaporation of salt solutions in pore space [9].

Sandstone characteristics, slope aspect, and lichen coverage also have an effect on weathering rates. Susceptibility to weathering is positively correlated with increasing grain size and increasing porosity in sandstones [13]. Disi sandstone is more friable than Umm Ishrin sandstone making it more susceptible to weathering. The effect of slope aspect on intensity of weathering was studied by Paradise $[11,12]$ on Djinn blocks (large rocks shaped into a cube-like form). In one case weathering was highest on the E-W faces and lowest on the $\mathrm{N}$ face, yet in another case weathering was lowest on the $\mathrm{E}-\mathrm{W}$ faces and highest on the $S$ face. Lichen thali cover $>50 \%$ of the surface on some north facing sandstone surfaces. Lichens appear to decrease the overall surface recession where they cover original stonedressing marks [14]. Sandstone recession rates, calculated as the ratio of distance between the original surface with stone-dressing marks to the present surface over the elapsed time period ( 2000 years), range between $10-220 \mathrm{~mm} / \mathrm{kyr}$ at horizontal and vertical surfaces of a Roman theatre and djinn blocks [10-12]. Heinrichs [13] reported maximum recession rates at portions of the monuments at $350 \mathrm{~mm} / \mathrm{kyr}$, but for whole monuments the average rates are $<80 \mathrm{~mm} / \mathrm{kyr}$. The recession rate is higher in friable younger sandstone. The recession rate is assumed to increase exponentially with time [13, Fig. 13]. No disintegration is expected in first $500-1000$ years after finishing the monuments while more than $50 \%$ recession is 
expected to occur in last few hundred years, but these estimates are unsupported by direct measurements [13].

\subsection{Střeleč locked sands (SLS)}

For physical modeling of weathering of Petra monuments (described in Section 3.3) we used Střeleč locked sand (referred to hereafter as SLS) from lower part of Střeleč Quarry, situated 70 km NE of Prague, Czech Republic. SLS is part of the Hrubá Skála Formation, which is a Cretaceous marine sandstone of upper Turonian and Coniacian age deposited in a shallow environment as coarse delta bodies [21]. $\mathrm{SiO}_{2}$ content varies between $95-99 \%$. The fine fraction $(<25 \mu \mathrm{m})$ is composed of well-ordered kaolinite $(75 \%)$, quartz $(24 \%)$, and illite $(1 \%)$. Non-dispersive kaolinite was identified as the only mineral binding agent [22]. For other SLS characteristics see Bruthans et al. [8].

Generally, cohesion in locked sand results from interpenetrative fabric of quartz grains due to diagenetic processes reducing the porosity [23]. Similar to other locked sands, SLS has high strength, high peak friction angle, high critical state friction angle, and brittle behavior (Table

1) $[8,23,24,25]$. Explosives are needed to separate material in the quarry (scale of tens of meters), but a cube of the same material with an edge length of $3 \mathrm{~cm}$ is so fragile that it cannot be lifted by hand. SLS is so friable that it can be disaggregated by brushing the surface and it disintegrates when fully immersed in water (without external load). Locked sand samples are less stable with diminishing size [26]. The origin of locked sands is attributed to a pressure solution of detrital quartz grains [27], which results in a interlocked texture (quartz grains with crystal overgrows - pyramidal truncations [23]). Based on experimental evidence the three processes responsible for disintegration and erosion of SLS in the quarry are raindrop impact, overland flow, and slaking. Slaking is caused by excess air pressure in capillaries that is generated by surface tension forces of water that enters the pores previously occupied by air. The entrapped air in the pores exerts pressure on the sides of the pores that is sufficient to break loose the material [28]. However, erosion of SLS by all of these processes can be completely stopped by applying high enough stress (>2 kPa) [8]. 


\section{Methods}

\subsection{Field observations and measurements}

Particular objects within the ancient city of Petra and surrounding natural sandstone landforms were richly photo-documented (Fig. 2). We focused on both natural and artificial forms that displayed the apparent effect of the stress-controlled weathering and erosion. These features included hourglass-shaped pillars, honeycomb structures, and arches.

\subsection{Laboratory measurements and analyses}

The effect of stress on salt weathering of Umm Ishrin sandstone was studied by applying different uniaxial loads to six cube samples with 4-cm long edges. Two unconfined cubes were left bare (PJa and PJb), touching only on their lower base. Figure 3 shows the two different types of cube compression. Two cubes—PJ1 and PJ2—were loaded by lead weights of 5.9 and $11.5 \mathrm{~kg}$, respectively. The other two cubes—PJ3 and PJ4—were compressed by placing $4 \mathrm{~cm} \times 4 \mathrm{~cm}$ steel plates on opposite sides of the cubes and tightening nuts on the steel casing constructed around the cubes with a torque screwdriver to 0.30 and $0.70 \mathrm{Nm}$, respectively. The corresponding confinement (in $\mathrm{MPa}$ ) for each cube was determined by calibration with a tensiometer. Uniaxial stress values were $36 \mathrm{kPa}$ for PJ1, 70 $\mathrm{kPa}$ for PJ2, $\sim 250 \mathrm{kPa}$ for PJ3, and $\sim 680 \mathrm{kPa}$ for PJ4. Based on a mean sandstone density of $\sim 2.4 \mathrm{~g} / \mathrm{cm}^{3}[11]$ these values are equivalent to an overburden thickness of $1.5 \mathrm{~m}$ for PJ1, 3 $\mathrm{m}$ for PJ2, $11 \mathrm{~m}$ for PJ3, and $30 \mathrm{~m}$ for PJ4.

All cubes were exposed to repeated 24-hour cycles where they were submerged in $16 \%$ $\mathrm{Na}_{2} \mathrm{SO}_{4}$ solution at room temperature for 2 hours, dried in an oven for 20 hours, and left to cool at room temperature for 2 hours. During the drying step, the temperature gradually increased from $25^{\circ} \mathrm{C}$ to $105^{\circ} \mathrm{C}$ in the first 7 hours and then remained stable at $105^{\circ} \mathrm{C}$ for 13 hours. The cubes were weighed after each cycle. This method follows the procedure of EN12370 [29] except that a higher concentration of $\mathrm{Na}_{2} \mathrm{SO}_{4}$ was used to increase disintegration rates [8]. 


\subsection{Physical and numerical modeling}

Whereas the effect of stress on weathering and erosion of cemented sandstones cannot be directly observed in the field due to slow weathering rates, we conducted physical modeling experiments using SLS, in which erosion proceeds instantly. Field experiments were done in situ at the Střeleč Quarry $50 \mathrm{~m}$ below the original ground surface on intact blocks of SLS. Surface crusts (if present) were carefully removed. Two simplified small-scale models of Petra monuments were carved into the sandstone using a hand drill with a core bit and were smoothed with a spatula. Models replicated only the most basic features of Petra monuments, including rectangular chambers, openings, columns, vertical facades. Models were subjected to water erosion using a hose with a sprinkler fed by a pump (model 1) or by manual watering with a water can (model 2). Erosion progress was photo-documented in steps defined either by important changes in model shape or by the amount of applied water. Numerical modeling was used to predict stress distribution within the physical models of Petra monuments constructed of SLS at Střeleč Quarry. The numerical modeling was performed using the geotechnical software PLAXIS 3D. Two finite element models were set up, one for each of the physical models. Model dimensions were exactly the same as dimensions of the physical models and model geometry closely resembled the geometry of the physical models (Figs. 4, 7a and 8a). Finite element meshes of models 1 and 2 consisted of 508,000 and 338,000 tetrahedral finite elements with second-order interpolation of displacements, respectively. Boundary conditions of the model were as follows: the displacement of the bottom boundary was fixed in both the horizontal and vertical directions, and the displacement of the vertical boundaries was fixed in the horizontal direction only.

SLS was described using a Mohr-Coulomb constitutive model. Young's modulus of $E=606.3$ MPa was calibrated on the basis of measurements of shear wave propagation velocities. Poisson's ratio was estimated as nu=0.25. The friction angle of $S L S$ is $\varphi=72^{\circ}$ [8]. Cohesion was calculated from the given friction angle and from uniaxial compression strength of $3 \mathrm{MPa}$ as $\mathrm{C}=238 \mathrm{kPa}$. The angle of dilatancy was estimated as $\psi=24^{\circ}$. The SLS total density was 
estimated as $\rho=2067 \mathrm{~kg} / \mathrm{m}^{3}$. This unit weight was calculated from the measured porosity of locked sand of $n=0.22$ and from the specific gravity of quartz $\left(G_{s}=2.65 \mathrm{~g} / \mathrm{cm}^{3}\right)$.

Stress state within the physical model was generated using the gravity loading procedure available in software PLAXIS 3D. Stress is generated during finite element simulation. The initial stress was prescribed as zero along with zero gravity acceleration. During the stress generation stage, the gravity acceleration was gradually increased to the value of $g=9.81$ $\mathrm{m} / \mathrm{s}^{2}$ under the condition of constant density.

\section{Results and discussion}

\subsection{Stress-controlled landforms in Petra}

Stress-controlled weathering/erosion landforms are ubiquitous in the Petra area - visible on both manmade and natural forms. Pillars and arches are typical for natural surfaces including tafoni and honeycombs (Fig. 2a, b). Sandstone blocks that are separated by fractures from adjacent massive sandstone quickly disintegrate unlike the massive sandstone in their immediate surroundings (Fig. 2c). The mechanism of stress-controlled weathering/erosion is also observable on artificial forms. Originally rectangular openings are remodeled into oval or irregular but rounded openings (Fig. 2d-f, for explanation see supplementary figure 15 in Bruthans et al. [8]). Sidewalls between two openings in tombs change into hour-glass pillars, which are parallel with principal stress direction. These pillars act as natural properly placed buttresses (Fig. 2e, g). Some tomb entrances have been remodeled into freestanding arches (Fig. 2h). Protrusions, like friezes and sculptures have been obliterated (cf. also Bruthans et al. [8], supplementary figure 19). Horizontal fractures and thin horizons of easily weathering material, which interrupt the continuity of the sandstone mass are responsible for strong decrease of stress magnitude above and below the subhorizontal discontinuity. As a consequence the sandstone will be quickly removed above and below discontinuity forming vaulted opening (similar to "architectural arcades"). Stress lines might be visible at places (cf. and Supplementary Figs. 8 and 15e in Bruthans et al. [8]). 


\subsection{Salt weathering experiments with Umm Ishrin sandstone}

Salt weathering experiments clearly demonstrated the inverse relationship between stress intensity and decay rate of cubes of Umm Ishrin sandstone. Fig. 5a shows a graph of actual mass $\left(m_{i}\right)$ normalized by the initial mass $m_{0}$. The fastest decay rate was observed for the unconfined cubes, similar to results of previous experiments using sandstones from the Czech Republic and USA [8]. The higher the loading, the higher number of weathering cycles the cubes survived, except PJ3, which lasted longer than PJ4. Unconfined cubes disintegrated after 9 to 13 cycles. Cubes loaded with pressures of $36,70, \sim 250$, and $\sim 680$ kPa disintegrated after 15, 26, 49, and 44 cycles, respectively. Figure $5 \mathrm{~b}$ shows the volume change per salt weathering cycle $\left(\mathrm{dV}_{\mathrm{i}}\right.$; incremental volume change) normalized by the current surface area of the sample $\left(A_{i}\right)$. The samples loaded by a lead weight (PJ1 and PJ2) showed consistent decrease of normalized incremental volume change with load (apart from the initialization of the disintegration process). Results of the samples compressed by steel plates (PJ3 and PJ4) cannot be decisively represented in this graph, as the actual stress during the salt weathering cycle is not precisely known. Fig. 5b also includes an exponential fit using equation

$$
\frac{d V_{i}}{A_{i}}=R_{0} e^{-\alpha \sigma}
$$

where $R_{0}$ is the disintegration rate for zero stress, $\sigma$ is current stress, and $\alpha$ is a fitting parameter. The exponential fit in Fig. 5 was obtained with $R_{0}=0.22 \mathrm{~mm}$ and $\alpha=0.006$. Salt weathering experiments resulted in rounding of cubes. Cube edges disintegrated within 4 cycles of salt weathering in case of unconfined cubes. For loaded cubes, rounding occurred after 4 - 9 cycles depending on the load. Unconfined cubes underwent spheroidal weathering, while loaded cubes weathered into pillars (Fig. 6). Disintegration of all cubes was associated with formation of surface salt crust, which peeled off with sand grains during 
soaking in $\mathrm{Na}_{2} \mathrm{SO}_{4}$ solution. The formation of a thick crust was responsible for delayed decay of PJa and PJb cubes between the $3^{\text {rd }}$ and $6^{\text {th }}$ cycles (Fig. 5a). The decay rate of loaded cubes temporarily increased after 1-5 initial cycles. Afterwards the decay rate gradually decreased to minimum values.

\subsection{Physical modeling with Střeleč Locked Sand}

Physical modeling with SLS was used to demonstrate the effect of the stress-controlled erosion on simplified models with rectangular openings and "chambers". Model 1 consisted of one chamber with two portals (Fig. 7a), two windows, three pillars and a vertical facade. Immediately after onset of erosion the sharp edges become rounded (Fig. 7b). The rectangular cross-section of pillars changed to an oval or circular shape. Rectangular openings likewise changed to an oval or irregular but rounded shape. The flat frontal wall of the chamber changed to an undulating surface (Fig. 7c). Erosion was generally higher in straight segments relative to the corners of the openings. Erosion followed horizontal fractures (see thinning of pillar A guided by a fracture). After a fast initial change, pillar $\mathrm{C}$ gradually thinned and finally eroded completely (Fig. 7d, Suppl. video 1). In the same period the other pillars and ceiling were not changed because pillar $C$ was not critical for supporting the ceiling of the chamber. Later pillar A was lost, which launched fast erosion of the ceiling above the pillar. Next, pillar B was lost, which launched massive and fast erosion of whole ceiling now unsupported by any buttress (Fig. 7h). Finally, all pillars and openings disappeared and only the parts of the ceiling that were supported by the protruding part of back-wall remained. The only parts showing artificial origin were the bottom of the chamber and remnants of originally rectangular corners (Fig. 7i).

Model 2 consisted of two chambers in different levels connected by corners, three portals and one column, vertical facades, and a flat bottom in the forefront (Fig. 8a). Similar to model 1 , the rectangular edges became rounded and rectangular cross-section of pillars became more circular quickly after onset of erosion (Fig. 8b). The pillar gradually thinned and finally eroded and the flat forefront was completely eroded away (Figs. 8e and 8f, Suppl. video 2). 
Another pillar was formed at place B, where SLS was bordered from all sides by free space due to interconnection of both chambers. Both chambers progressively merged together as erosion removed the material between the chambers (Fig. 8i). The evolution of pillar diameters is shown in Fig. 9. Initially the pillar diameter decreased quickly by $\sim 20 \%$ as edges were lost but then the recession rate decreased. Finally, once overburden recessed until the pillar lost its loading, the pillar eroded away very quickly.

Shapes resulting from experimental erosion of SLS blocks are strikingly similar to shapes visible present-day in Petra monuments (Figs. 2 and 10). Based on the erosion progress of both models we conclude that the recession rate is far from constant both in space and time despite the fact that SLS had similar potential erodibility in each model. The recession rate was highest at those portions of model that were least loaded at given time and on the edges, where stress cannot effectively stabilize the material (angle inside of material $\leq 90^{\circ}$ ). On the other hand, a lower recession rate was observed at loaded surfaces. An abrupt increase of recession rate was observed whenever buttress elements were lost (e.g., pillar or supporting wall). In such a case the material, which previously transferred the load through the pillar, was quickly eroded away (all material in ceiling and also at a base of a former pillar). Also, the recession rate was very high at the beginning of the experiments since artificial activity significantly disturbs the original stress field of the previously quasi-stable natural landscape. Local horizontal fractures disturbed the stress field, which led to increased erosion of material directly above and below the fractures.

\subsection{Numerical modeling}

Distribution of major principal stress within the two finite element models is shown in Fig. 11a. The major principal stress is at a maximum at the inner corners of the 3D model, with intermediate values in the columns and walls of the modeled monument and minimum values just above the lintels of doors and windows and along the outer corners due to the arching effect. A similar picture is given by model cross-sections with principal stress magnitudes and directions (Fig. 11b). The stress agrees with the observed tendency of the monument shapes 
to become "rounded" (see Figs. 7 and 8): inner corners (angle inside of material $270^{\circ}$ ) are least susceptible to erosion due to stress concentration, whereas lintels are most susceptible to erosion. In the course of the erosion process, rounding of the geometry relieves stress concentration in the corners. This agrees with the experimental observation that the erosion continues evenly along the surface in the latter erosion phases. However, columns and walls are always more resistant to erosion, as the major principal stress is larger within them than in the surrounding material.

The stress magnitude is quantified in Fig. 11c, showing areas in different color where the major principal stress is higher and lower than the approximate limiting value of $2 \mathrm{kPa}$. As indicated by Bruthans et al. [8], this value (quantified to lie within the broader range of $1 \mathrm{kPa}$ to $8 \mathrm{kPa}$ ) is limiting for the locked sand disintegration by surface slaking due to water inundation. Fig. 11c clearly shows that the initial erosion is to be expected in the door and window lintels, along the outer corners of the geometry and, in general, along the top, nonloaded surfaces of the model. This agrees with the experimental observations (see Figs. 7b and $8 \mathrm{~b}$, the first two photos just after the onset of erosion process).

\subsection{Synthesis of measured data and field observations}

Detailed inspection of several tens of tombs in various locations in Petra showed that recession is concentrated in external tomb façades, tomb portals, and their immediate vicinity. On the contrary, the stone-dressing marks are often preserved inside the tomb chambers, which show no surface recession in last $2000 \pm 200$ years. Interestingly, the amount of the salts is often highest in the tomb interiors and salts sometimes cover the stone-dressing marks by several mm thick crusts (e.g., at the Ad-Deir Monastery). XRD analyses show that the major salts in the tombs interiors are halite and gypsum, the same salts that are responsible for decay of facades $[9,13]$. This clearly demonstrates that exposure type is a more important factor than salt concentration for sandstone decay. The highest decay rates of sandstone were observed on vertical and overhanging outer tomb walls, where periodically flowing gravitational water carries salts and evaporation dominates 
over leaching. Water periodically dissolves salts, which otherwise act as cement, to release the decayed sandstone. Salts can re-precipitate after each heavy rain, which increases damage to the sandstone pore spaces. Salt dissolution and re-precipitation does not occur in the interior of the tombs because there is no temporary water saturation, and thus damage is considerably lower than on outer surfaces. An alternative explanation of prevailing damage on external surfaces might be insolation, which increases damage by thermal "salt explosion" of halite [30] or high supersaturation during halite precipitation due to rapid drying [31]. Very fast recession rate of tomb ceilings and forefronts was observed on some portions of sandstone monuments located at lower elevations in Petra (Fig. 10). A similar pattern of erosion was observed on sloping surfaces of SLS after pronounced erosion period (Suppl.

Fig. 1). Erosion dominates on sloping surfaces exposed to the rain where erosion rates may exceed $1000 \mathrm{~mm} / \mathrm{kyr}$. Salts tend to be leached from sloping surfaces and thus salt weathering is unlikely to cause such rapid decay. Slaking or swelling clays might be responsible for rapid decay, but detailed study is needed to test this hypotheses.

The observation that recession occurs only on some exposure types should be considered in any conceptual model of sandstone decay of Petra monuments. Decay will be fastest at places where salt or other weathering is intensive and stress magnitude is low. A lower decay rate will occur at places with similar intensity of weathering factors (e.g., salt concentration) but with higher stress magnitude. No recession will occur at places where salt weathering (or other weathering) does not occur.

\section{Conclusion}

The ubiquitous presence of stress-controlled landforms at the Petra World Heritage Site shows a substantial effect of stress on weathering and erosion of artificial monuments and natural surfaces. Salt weathering experiments clearly demonstrated the inverse relationship between stress magnitude and decay rate, wherein unconfined cubes disintegrated 4 times faster than cubes loaded by 250-680 kPa. Physical modeling with Střeleč locked sands 
(SLS) used to simulate the erosion of Petra monuments resulted in shapes strikingly similar to highly weathered tombs. For the first time, the physical modeling enabled visualization of the erosion progress on monuments and suggests that the recession rate of Petra monuments is far from constant both in space and time. The recession rate is highest at portions of the monuments that are least loaded at any given time (e.g., protrusions or outer edges). An abrupt increase of recession rate occurs each time a buttress element is lost (e.g. pillars). Material that no longer transfers load is quickly eroded away. Numerical stress modeling agrees with the experimental observations.

Observations of tomb interiors and exterior revealed that the exposure type is another important factor in sandstone decay rate at Petra. High recession rates were observed on external surfaces shielded from direct rain but exposed to intense evaporation and temporary inflows of salt-carrying storm water. On the contrary, tomb interiors are often unaffected by decay despite abundant salt deposits, probably because of the absence of periodic saturation or lack of rapid drying by insolation. To properly delineate the endangered zone of monuments, the potential damage caused by weathering agents should be combined with stress modeling and verified by real damage mapping.

Our multi-approach study clearly documented that stress is an essential factor for controlling weathering rates of Petra monuments, with an inverse relationship between stress and decay rates. We conclude that potential effect of stress on weathering should be accounted for in any research dealing with the sandstone decay as even homogenous sandstone exposed to equal intensity of weathering (e.g. the same salt concentration) may decay at very different rates solely because of differences in stress magnitude.

\section{Acknowledgements}

This research was funded by the Czech Science Foundation (GA CR No. 13-28040S), the Grant Agency of Charles University (GAUK No. 386815) and supported by the research plan No. RVO 67985831 and RVO 67985891 . G.T.C. was supported by a Mentoring Environment 
Grant from Brigham Young University to Dr. Cynthia Finlayson. We thank Dr. Finlayson and the BYU Department of Anthropology for making the field work possible.

\section{References}

[1] B. Fitzner, K. Heinrichs, D. La Bouchardiere, Weathering damage on Pharaonic sandstone monuments in Luxor-Egypt, Building and Environment 38 (2003) 1089-1103.

[2] D. Mottershead, A. Gorbushina, G. Lucas, J. Wright, The influence of marine salts, aspect and microbes in the weathering of sandstone in two historic structures, Building and Environment 38 (2003) 1193-1204.

[3] T. Hosono, E. Uchida, Ch. Sudah, A. Ueno, T. Nakagawa, Salt weathering of sandstone at the Angkor monuments, Cambodia: identification of the origins of salts using sulfur and strontium isotopes, Journal of Archaeological Science 33 (2006) 1541-1551.

[4] H. Siedel, S. Pfefferkorn, E. von Plehwe-Leisen, H. Leisen, Sandstone weathering in tropical climate: Results of low-destructive investigations at the temple of Angkor Wat, Cambodia, Engineering Geology 115 (2010) 182-192.

[5] E. Gerber, A.E. Scheidegger, Stress-induced weathering of rock masses, Eclogae Geologicae Helvetiae 62 (1969) 401-415.

[6] E. Gerber, A.E. Scheidegger, Erosional and stress-induced landforms features on steep slopes. Zeitschrift fuer Geomorphologie, Supplement 8 (1973) 38-49.

[7] H.A. Viles, Scale issues in weathering studies, Geomorphology 41 (2001) 63-72.

[8] J. Bruthans, J. Soukup, J. Vaculikova, M. Filippi, J. Schweigstillova, A.L. Mayo, D. Masin, G. Kletetschka, J. Rihosek, Sandstone landforms shaped by negative feedback between stress and erosion, Nature Geoscience 7 (2014) 597-601.

[9] W. Wedekind, J. Ruedrich, Salt-weathering, conservation techniques and strategies to protect the rock cut facades in Petra/Jordan, in: R. Fort, M. Álvarez deBuergo, M. Gomez-Heras, C. VazquezCalvo (Eds.), Heritage, Weathering and Conservation. Taylor \& Francis, London. 2013, pp. 261-268. 
[10] T.R. Paradise, Sandstone weathering therholds in Petra, Jordan, Physical Geography 16 (1995) 205-222.

[11] T.R. Paradise, Sandstone weathering and aspect in Petra, Jordan, Zeitschrift für Geomorphologie 46 (2002) 1-17.

[12] T.R. Paradise, Assessment of tafoni distribution and environmental factors on a sandstone djinn block above Petra, Jordan, Applied Geography 45 (2013) 176-185.

[13] K. Heinrichs, Diagnosis of weathering damage on rock-cut monuments in Petra, Jordan, Environmental Geology 56 (2008) 653-675.

[14] T.R. Paradise, Petra revised: An examination of sandstone weathering research in Petra, Jordan, Geological Society of America Special paper 390 (2005) 39-49.

[15] G. Strijker, G. Bertotti, S.M. Luthi, Multi-scale fracture network analysis from an outcrop analogue: A case study from the Cambro-Ordovician clastic succesion in Petra, Jordan, Marine and Petroleum Geology 39 (2012) 104-106.

[16] O.A. Al-Khashman, lonic composition of wet precipitation in the Petra Region, Jordan, Atmospheric Research 78 (2005) 1-12.

[17] O.A. Al-Khashman, Study of water quality of springs in Petra region, Jordan: A three-year followup, Water Resources Management 21 (2007) 1145-1163.

[18] G. Delmonaco, C. Margottino, D. Spizzichino, Slope dynamic, monitoring and geological conservation of the Siq of Petra (Jordan), in: C. Viggiani (Ed.), Geotechnical Engineering for the Preservation of Monuments and Historic Sites, CRC Press, 2013, pp. 325-334.

[19] I. Reynolds, The History and Architecture of Petra, JCCC Honors Journal v3(i2), Article 3 (2012) Available at: http://scholarspace.jccc.edu/honors journal/vol3/iss2/3

[20] A.S. Goudie, P. Migon, R.J. Allison, N. Rosser, Sandstone geomorphology of the Al-Quwayra area of south Jordan, Zeitschrift für Geomorphologie 46 (2002) 365-390. [21] D. Uličný, Depositional systems and sequence stratigraphy of coarse-grained deltas in a shallow-marine, strike-slip setting: the Bohemian Cretaceous Basin, Czech Republic, Sedimentology 48 (2001) 599-628. 
[22] J. Bruthans, D. Světlík, J. Soukup, J. Schweigstillová, J. Válek, M. Sedlackova, A.L. Mayo, Fast evolving conduits in clay-bonded sandstone: Characterization, erosion processes and significance for origin of sandstone landforms, Geomorphology 177-178 (2012) 178-193.

[23] M.B. Dusseault, N.R. Morgenstern, Locked sands, Quarterly Journal of Engineering Geology \& Hydrogeology 12 (1979) 117-131.

[24] A. Cresswell, W. Powrie, Triaxial tests on an unbonded locked sand. Geotechnique 54 (2004) 107-115.

[25] T.S. Abdelaziz, C.D. Martin, R.J. Chalaturnyk, Characterization of locked sand from Northeastern Alberta, Geotechnical Testing Journal 31 (2008) 480-489.

[26] A.W. Cresswell, Block sampling and test sample preparation of locked sands, Geotechnique 51 (2001) 567-570.

[27] N.P. Richards, M.E. Barton, The Folkestone Bed sands: microfabric and strength, Quarterly Journal of Engineering Geology 32 (1999) 21-44.

[28] K. Arulanandan, R.T. Heinzen, in: Erosion and Solid Matter Transport in Inland Waters IAHSAISH, UNESCO (Eds.), 122 (1977) 75-81 (Adlard \& Son Ltd, Dorking, 1977).

[29] EN 12370 Natural stone test methods - Determination of resistence to salt crystallization, European standard EN12370:1999, European Committee for Standardization (1999).

[30] G. Kirchner, Phisikalische Verwitterung in Trockgebieten unter Betonung der Salzverwitterung am Beispiel des Basin-and-Range-Gebiets (Südwestliche USA and Nördliches Mexiko). Mainzer Geographische Studien. Geographisches Institut der Jonannes Gutenberg-Universitat 41 (1995), 267 pages.

[31] T. Lombardo, E. Doehne, S. Simon, The response of $\mathrm{NaCl}$ and Umm Ishrin sandstone to humidity cycling: mechanisms of salt weathering, in: The 10th International Congress on Deterioration and Conservation of Stone, Stockholm, 27 June - 2 July, 2004.

\section{Table 1}

Střeleč Locked Sand (SLS) properties. UCS - uniaxial compressive strength 


\begin{tabular}{|c|c|}
\hline Parameter & SLS \\
\hline porosity [\%] & 22 \\
\hline matrix content ( $\leq 25$ um) [\%] & 1.4 \\
\hline UCS dry [MPa] & $2.7-3.2$ \\
\hline UCS saturated [MPa] & 3.0 \\
\hline peak friction angle $\left[^{\circ}\right]$ & 74 \\
\hline peak cohesion $[\mathrm{kPa}]$ & 6 \\
\hline
\end{tabular}




\section{Caption for figures}

Fig. 1. Characteristic well-preserved original shapes of monuments in Petra: a) Portal in a chamber across from Ad Deir (Monastery); b) Al Khazna (Treasury). Human and animal figures in Al Khazna were damaged artificially (iconoclasm), not due to the weathering.

Fig. 2. Examples of stress-controlled natural (a-c) and artificial (d-h) forms in Petra: a) pillars in honeycombs; b) pillar; c) quickly disintegrating rock slab separated from the massive rock; d) tomb walls converted into pillars; e) inclined pillar; f) tomb weathered into rounded shapes; g) and h) strongly weathered tomb walls changed into pillars.

Fig. 3. Two different types of compression used for salt weather experiments: a) cube loaded by lead weight (used for cubes PJ1 and PJ2); b) cube compressed by tightening the nuts on the steel casing constructed around the cube (used for cubes PJ3 and PJ4).

Fig. 4. Geometry and finite element mesh of the two finite element models: a) model 1 ; b) model 2.

Fig. 5. Relationship between stress intensity and decay rate of Umm Ishrin sandstone cubes during salt weathering: a) total mass normalized by the initial mass; b) incremental volume change normalized by current surface area.

Fig. 6. Pillar originated by salt weathering of cube PJ3 after cycle number 33.

single, 1.5 -column fitting image

Fig. 7. Physical modeling of erosion progress of simplified architectural elements in Střeleč locked sand (model 1 with rectangular openings and chambers). See also animation of model erosion in supplementary material. Numbers in bottom right corners mark total time (minutes:seconds) of water addition. Knife length is $11 \mathrm{~cm}$. Hatched areas show the sandstone volume eroded from previous time period. Capital letters mark individual pillars (A-C) 
Fig. 8. Physical modeling of erosion progress of simplified architectural elements in Střeleč locked sand (model 2 with rectangular openings and "chambers"). See also animation of model erosion in supplementary material. Hatched areas show the sandstone volume eroded from previous time period. Numbers show number of water can volumes used for erosion. Capital letters mark individual pillars (A and $\mathrm{B})$

Fig. 9. Erosion rate of pillars in model 2 (Fig. 8). F pillar failure.

Fig. 10. Fast recession rate of tomb ceilings and forefronts: a), b) tombs with eroded front walls a) situated below Lions triclinium; b) situated near theatre; c), d) tombs with eroded ceiling and sidewalls near Temenos.

Fig. 11. PLAXIS modeling: a) distribution of major principal stress within the two finite element models; b) model cross-sections with principal stress magnitudes and directions; c) graphics showing areas in different color with major principal stress higher and lower than the limiting value of $2 \mathrm{kPa}$.

\section{Caption for tables}

\section{Table 1}

Střeleč Locked Sand (SLS) properties. UCS - uniaxial compressive strength

\section{Supplementary Material}

\section{Supplementary Figure}

Supplementary Fig. 1. Shapes of eroded rectangular chambers resemble the strongly eroded chambers in Petra, which lost frontal part and ceiling. 


\section{Supplemenary videos}

\section{Suppl. Video 1}

Physical modeling of erosion progress of simplified architectural elements in Střeleč locked sand (model 1 with rectangular openings and chambers). See also Fig. 7. Animation consists of photographs, which were taken to cover each stage of erosional progress. Whole sequence covers 34 minutes of real time.

\section{Suppl. Video 2}

Physical modeling of simplified erosion progress of architectural elements in Střeleč locked sand (model 2 with rectangular openings and "chambers). See also Fig. 8. Animation consists of photographs, which were taken after each refilling of water can used for erosion. Each individual frame thus means similar potential erosion applied. 

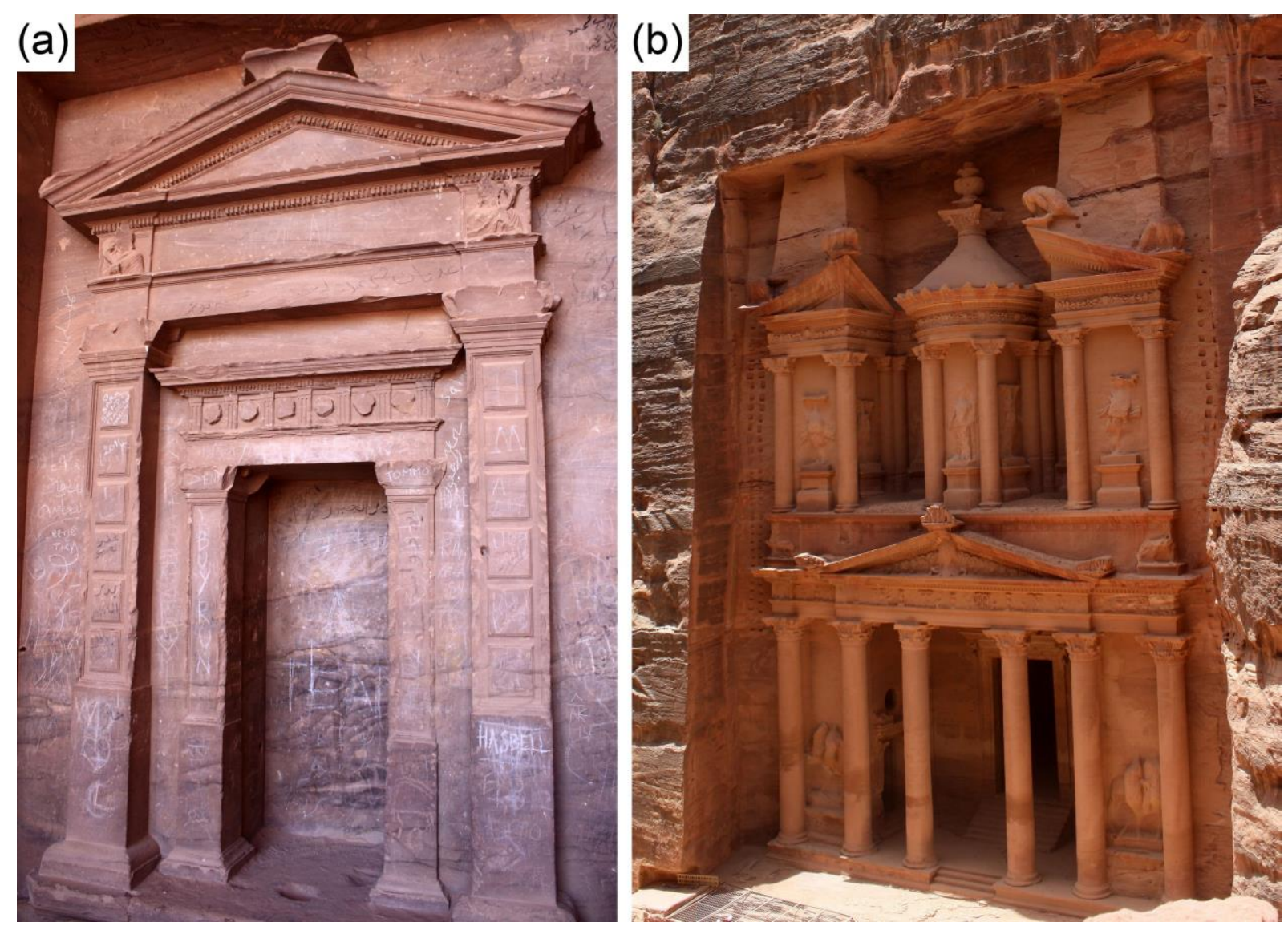

Fig. 1 

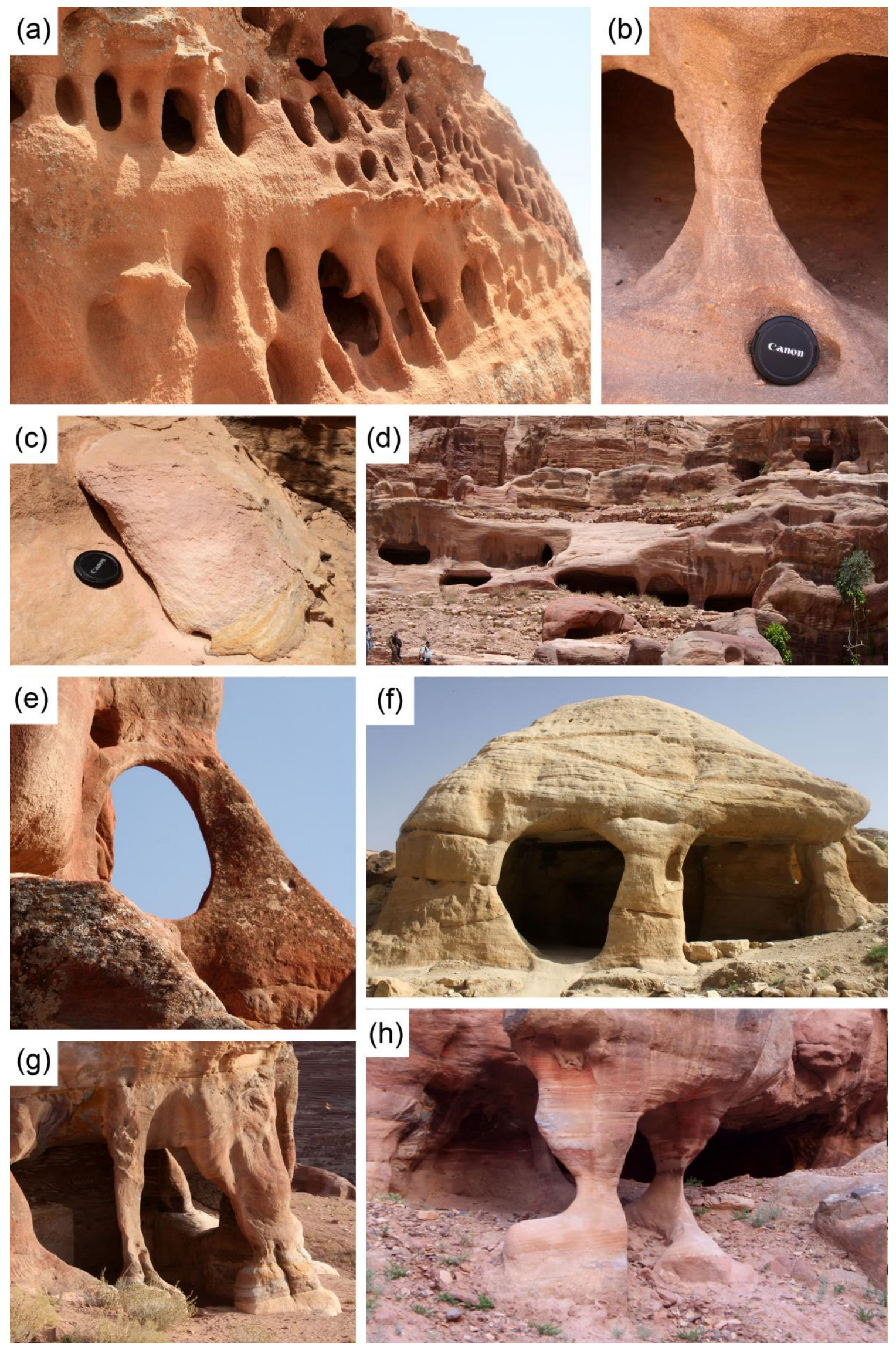

Fig. 2 

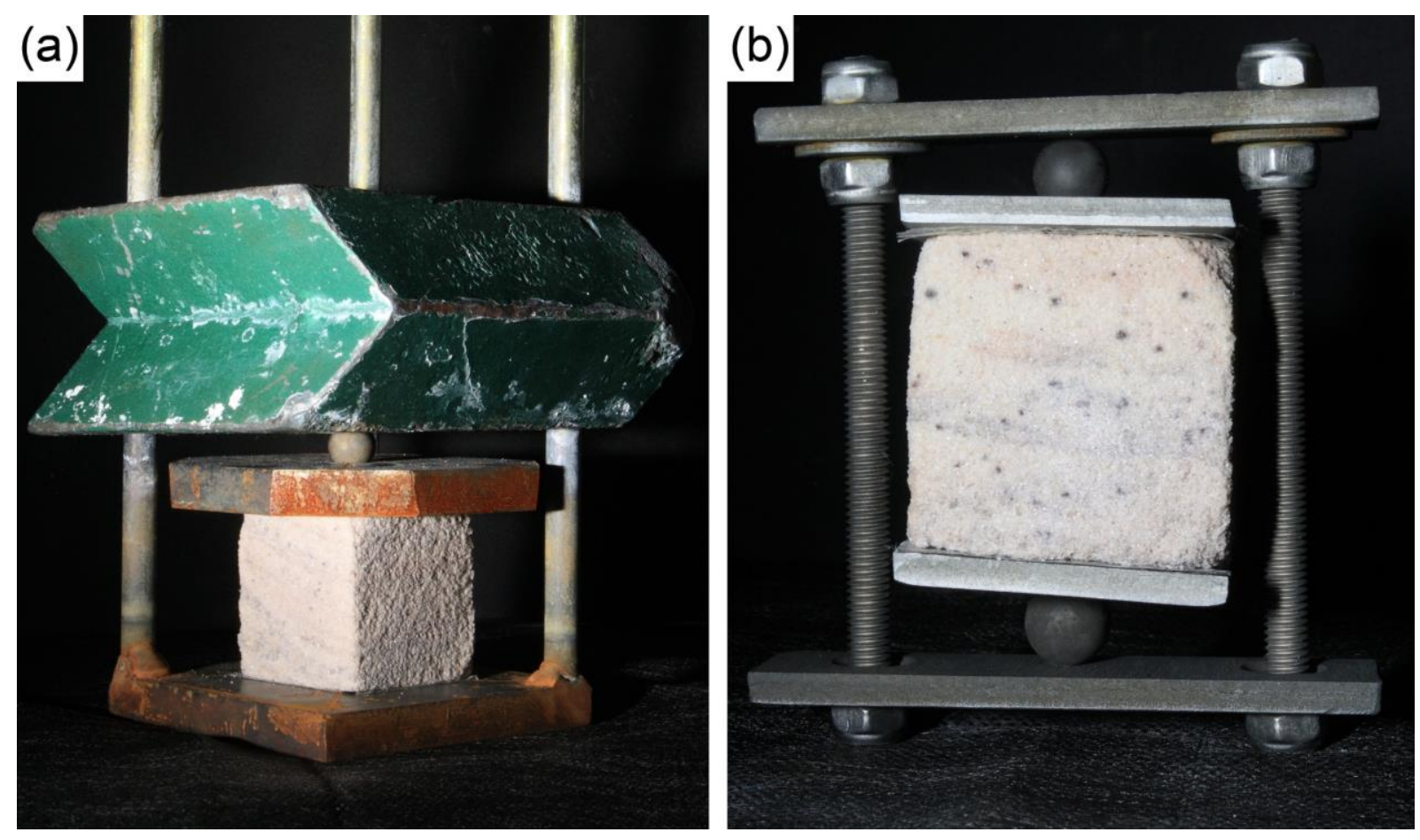

Fig. 3
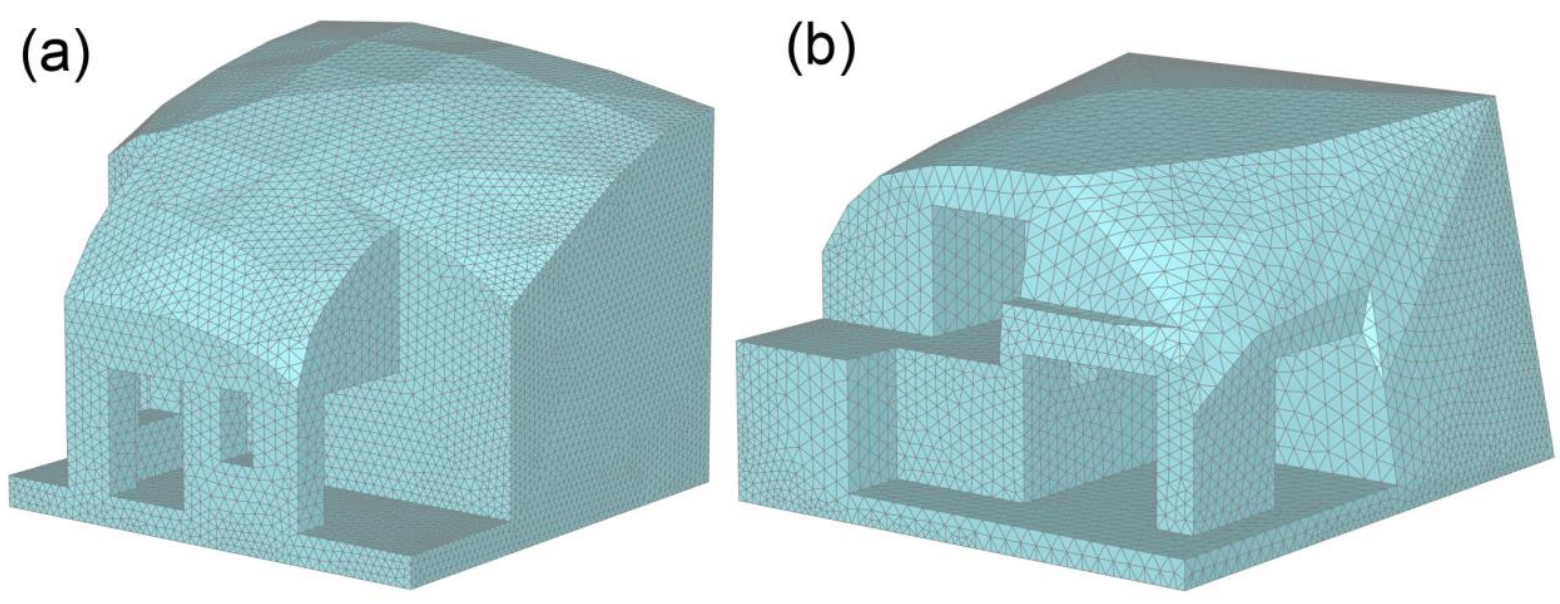

Fig. 4 
(a)

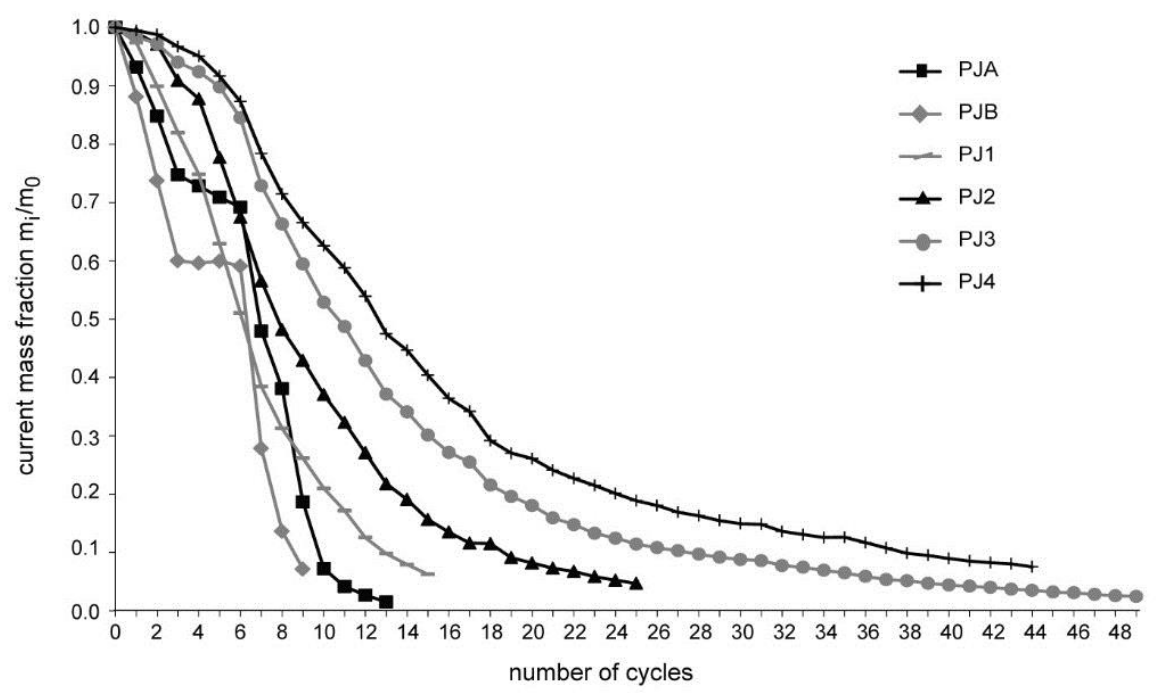

(b)

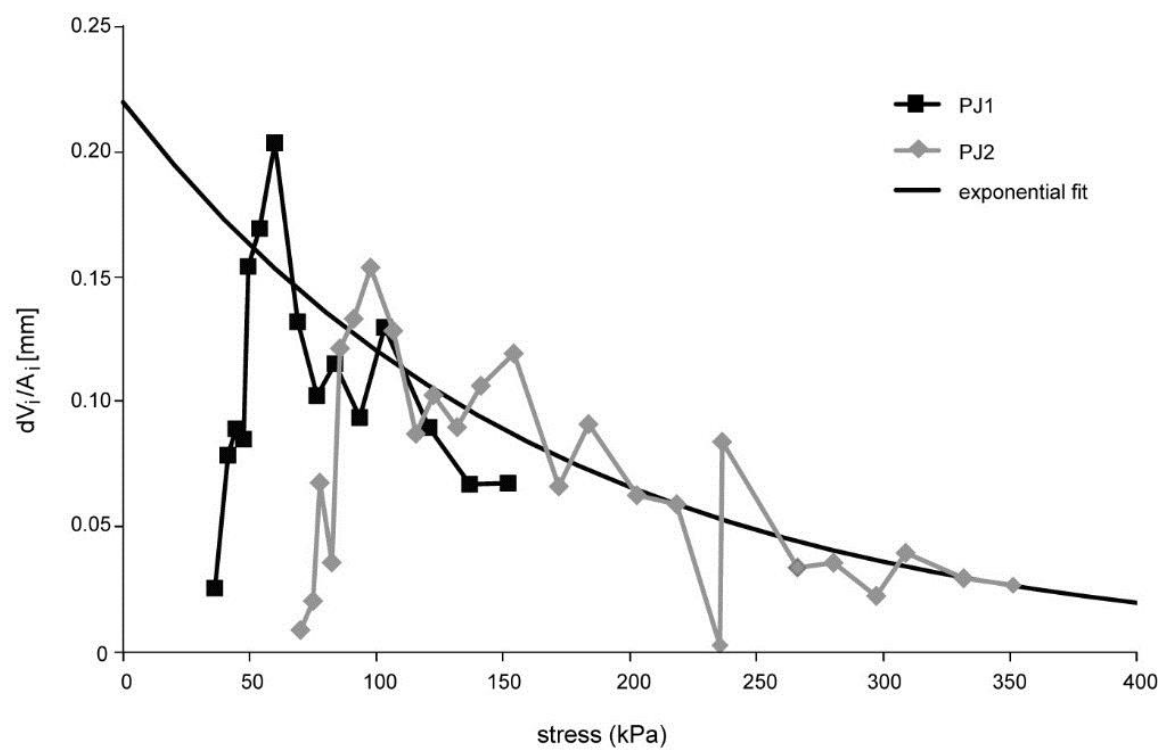

Fig. 5 


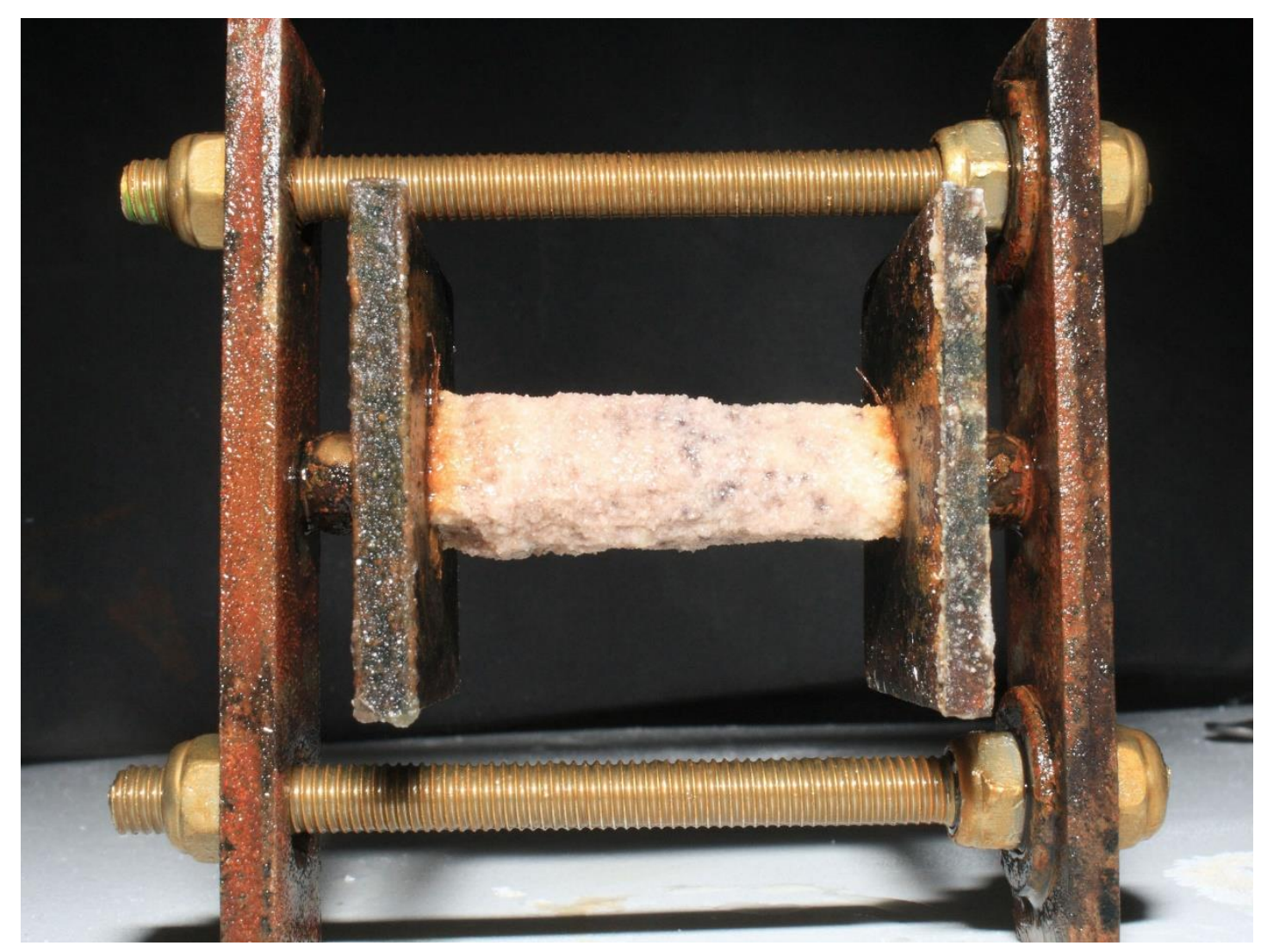

Fig. 6 

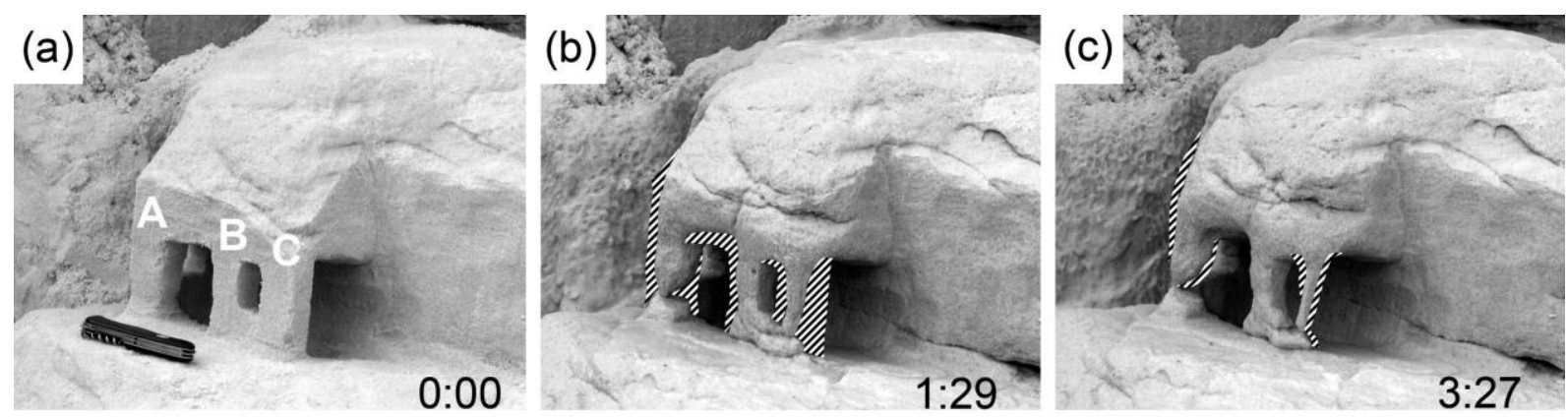

(d)
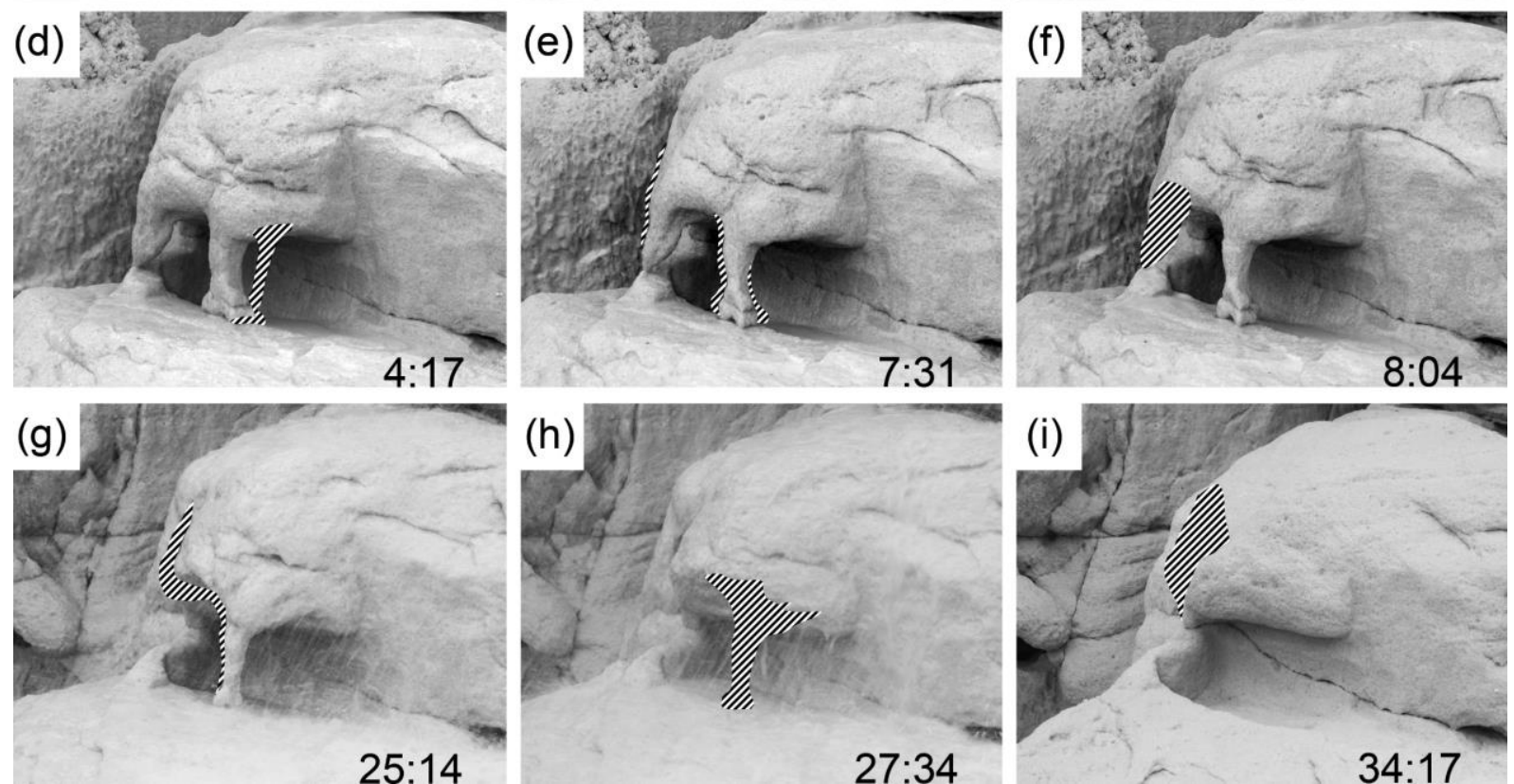

Fig. 7 

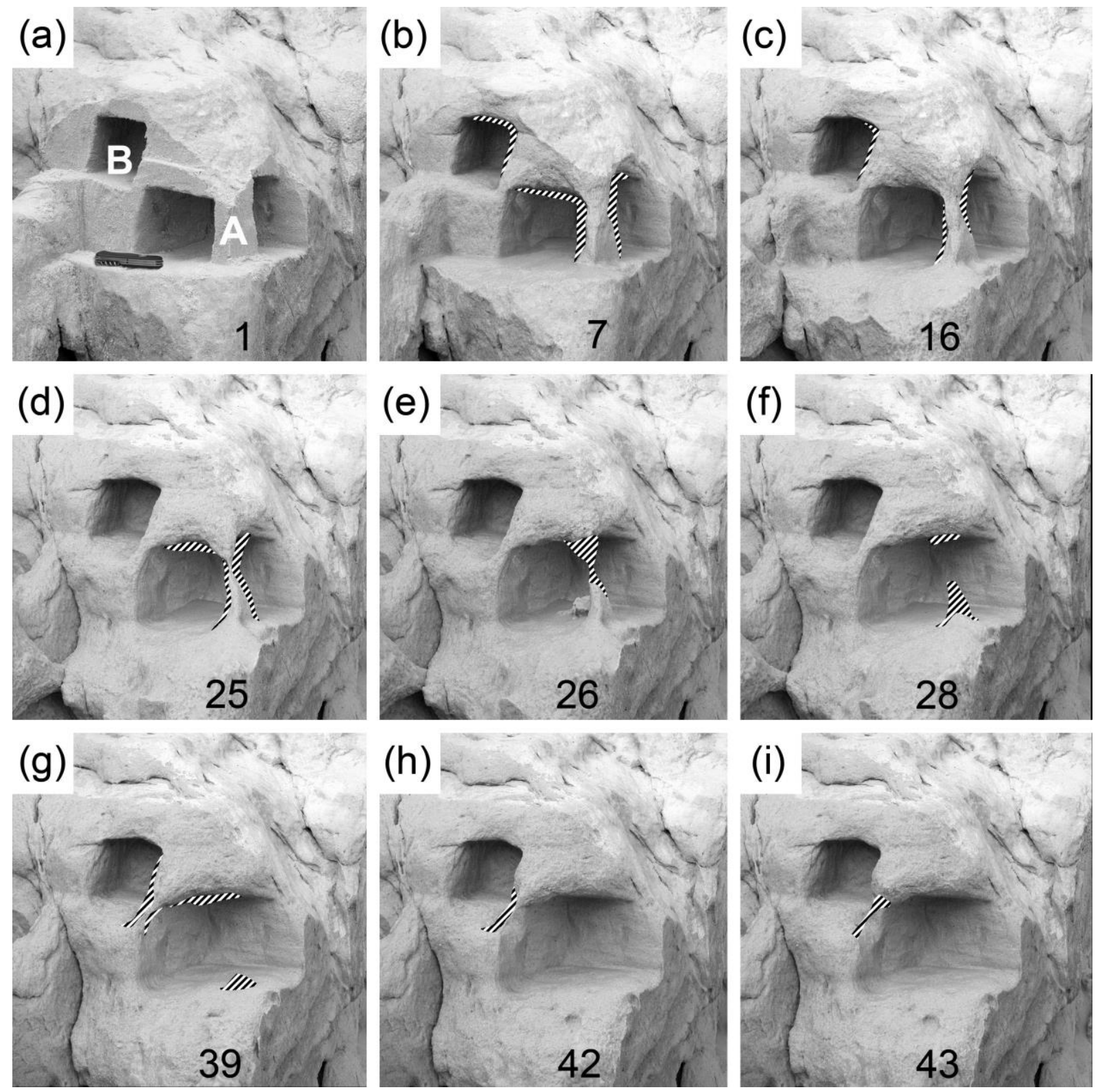

Fig. 8

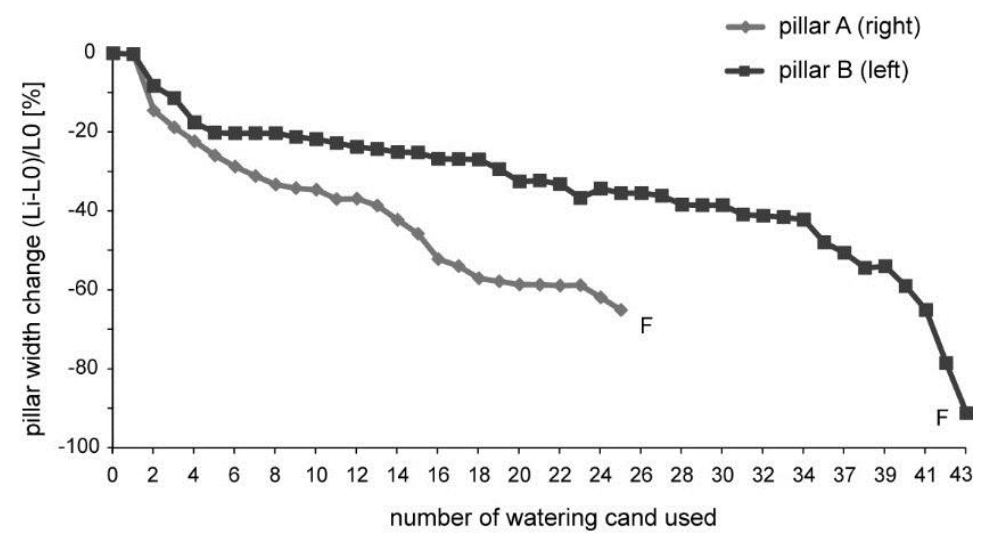

Fig. 9 

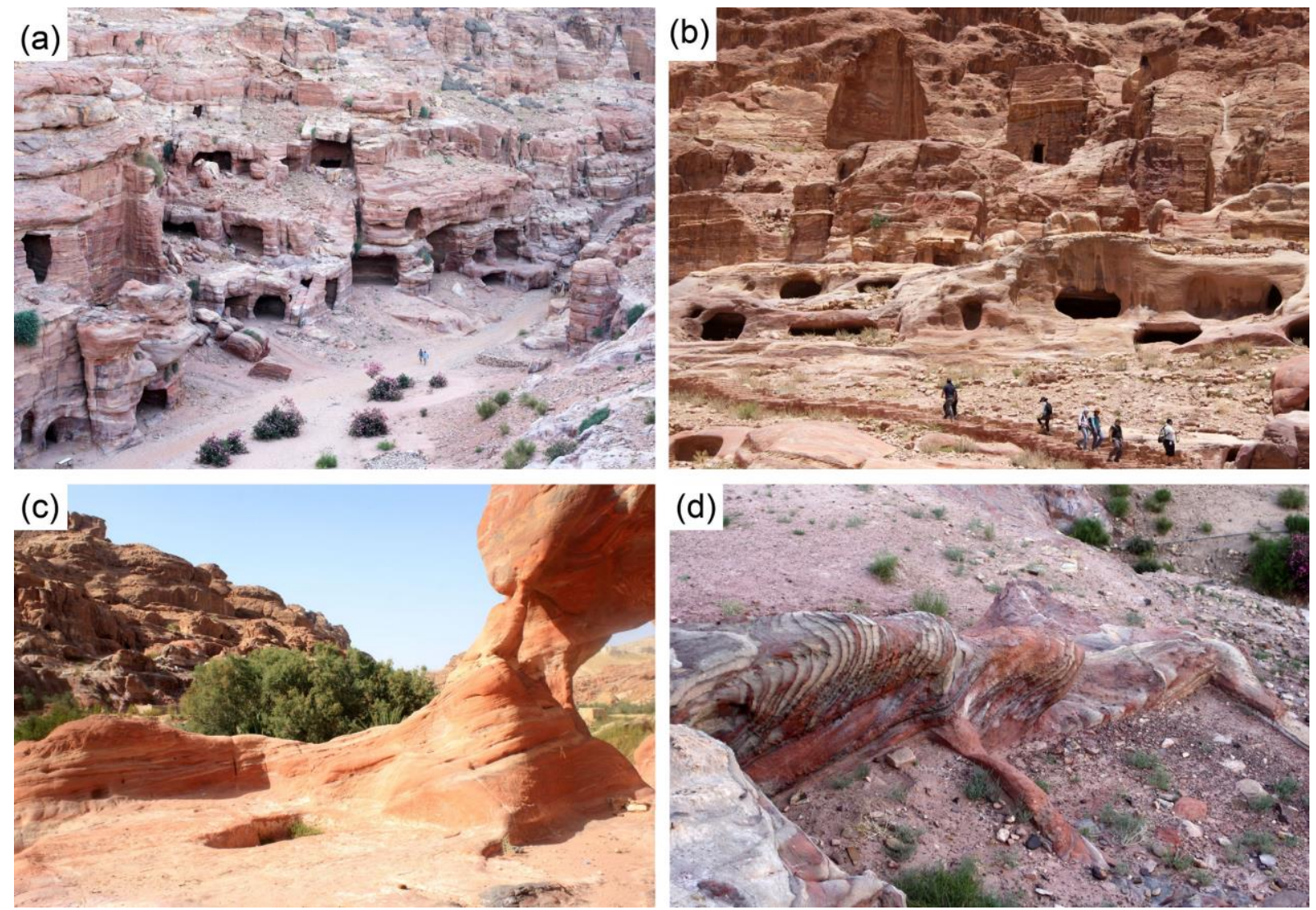

Fig. 10 


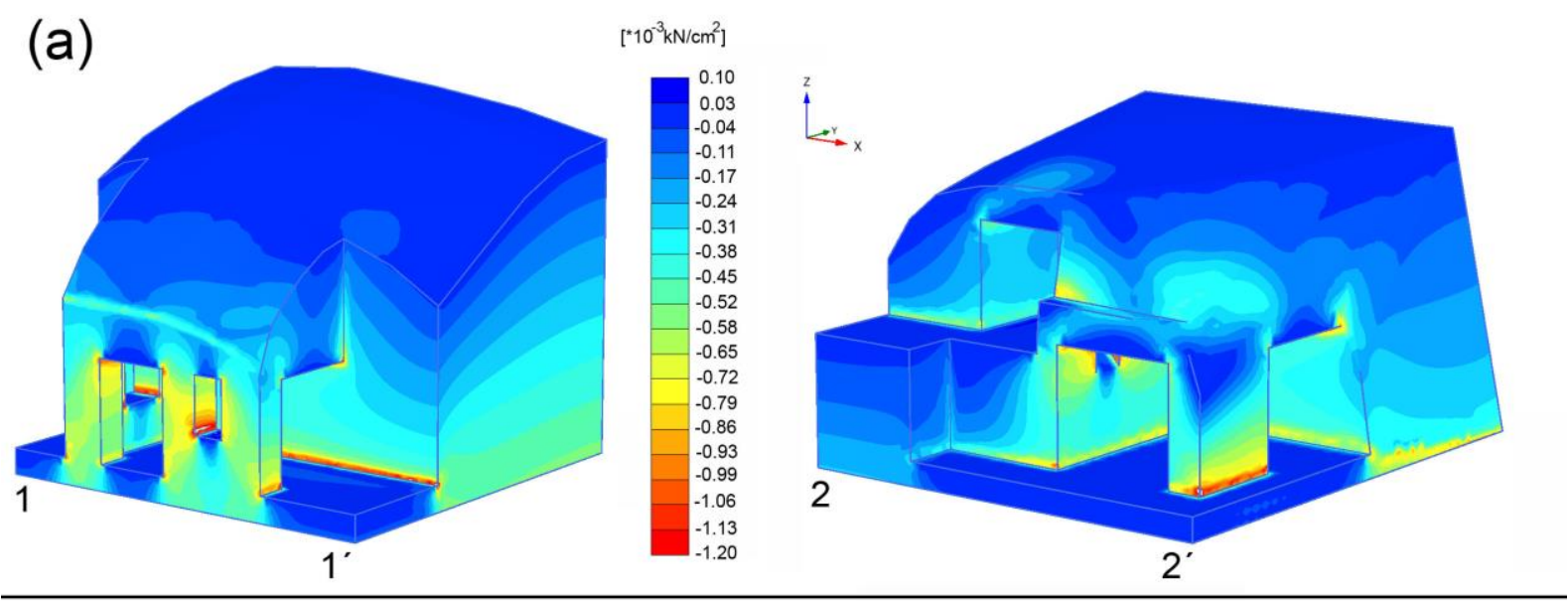

(b)
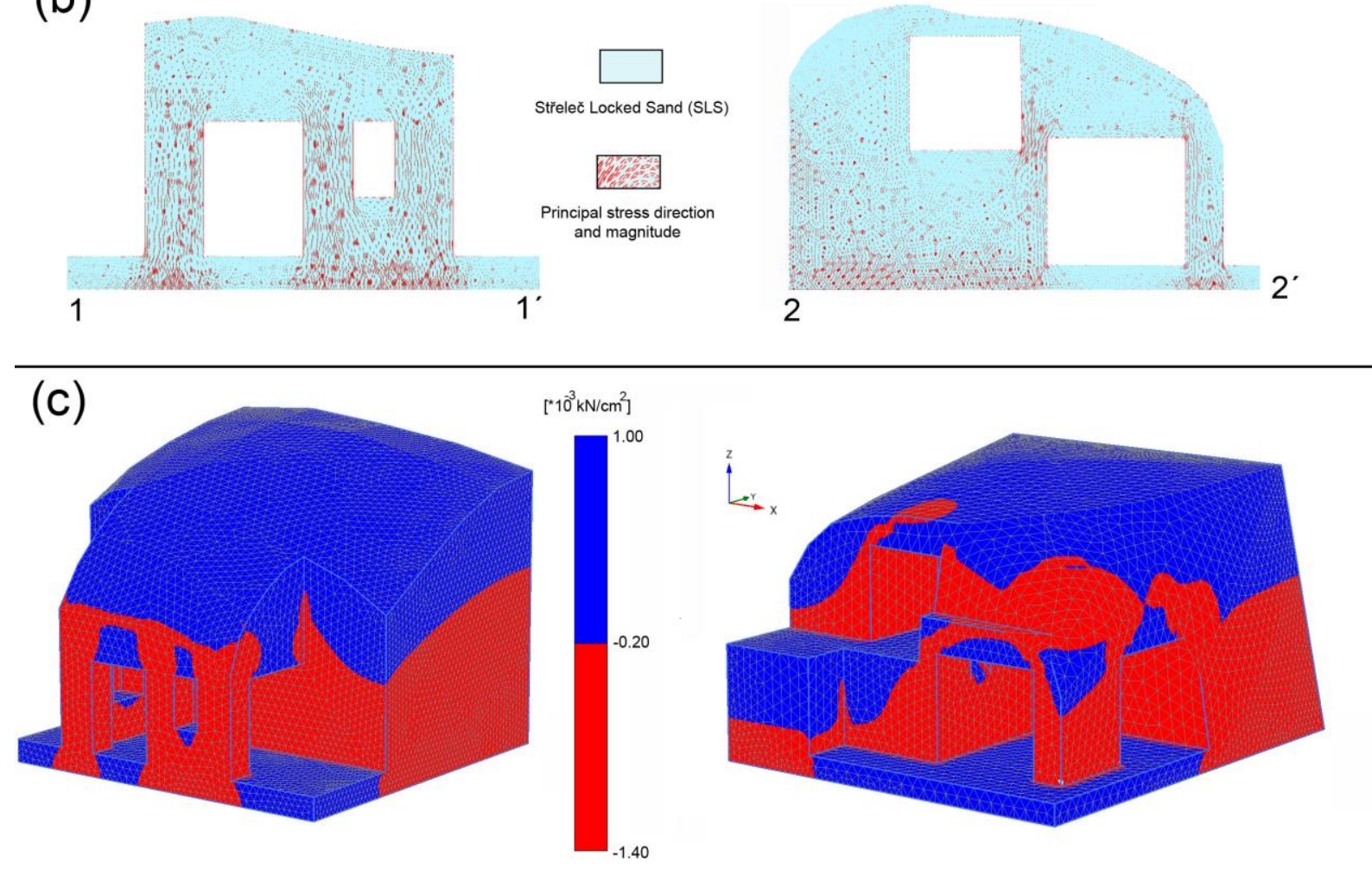

Fig. 11 